\title{
A Rehabilitation Gaming System for Cognitive Deficiencies: Design and Usability Evaluation
}

\author{
Ahmed Mohammed Elaklouk ${ }^{\#}$, Nor Azan Mat Zin ${ }^{*}$

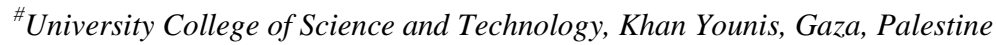 \\ E-mail: ahmed_aklouk@hotmail.com \\ *Center for Software Technology and Management, Faculty of Information Science and Technology, \\ Universiti Kebangsaan Malaysia, 43600 Bangi, Selangor, Malaysia \\ E-mail:azan@ukm.edu.my
}

\begin{abstract}
Patients with Acquired Brain Injuries or ABI experience various cognitive deficiencies that adversely impact their daily lives, as their ability to perform everyday activities, becomes severely limited. These patients would benefit more from engaging in unconventional cognitive rehabilitation, specifically rehabilitation using Serious Games. However, it is difficult to categorize cognitive disabilities due to their heterogeneity; therefore individualized rehabilitation interventions are required. It is also challenging to design games for cognitive rehabilitation, as the complexity and production cost for these games are usually very high. There is an abundance of recent studies on cognitive rehabilitation, particularly game-based interventions. However, some studies explain how to design games that are enjoyable and usable for patients with cognitive disabilities. Hence, this study addresses this issue with a proposed framework for therapeutic game developers targeting patients with cognitive deficiencies. To this end, a prototype Rehabilitation Gaming System (RGS) was developed and evaluated by therapists. A 7-point Likert scale usability questionnaire was used and the mean scores for layout/design (5.94), ease of use (5.40), easy to learn (5.76), usefulness (5.96) and satisfaction (6.1) indicate that RGS has good usability. Therapists are willing to use RGS for rehabilitation purposes. Practitioners, game developers, and patients in the healthcare field will be able to use the proposed framework as a guide and tool for designing and implementing games targeted for cognitive rehabilitation.
\end{abstract}

Keywords — acquired brain injuries; cognitive rehabilitation; serious game design; usability evaluation.

\section{INTRODUCTION}

Cognitive deficiencies are a hallmark of patients with ABI (Acquired Brain Injuries). Stroke (Cerebrovascular Accident) and Traumatic Brain Injury (TBI) are the two major ABI sources that cause disabilities in patients [1]. One of the most pressing problems that result from ABI is cognitive impairment. Following ABI, cognitive dysfunctions that are common include impairments in executive function, the speed of processing, language, communication, visuospatial perception, sensory-motor integration, recognition, concentration, memory, and attention [2]. Cognitive dysfunctions such as these significantly impact the lives of affected individuals and restrict them from going about their daily lives. To recover, patients undergo treatment centering on cognitive rehabilitation, where, to lessen the impact of cognitive dysfunctions, the patients will undergo therapeutic activities and techniques [1], [2]. Despite the promise of rehabilitation, this approach takes a long time, countless training sessions, and incurs expensive costs [3]. Also, patients tend to neglect prescribed recovery exercises because they feel that traditional rehabilitation exercises are repetitive and boring [3]. Recent work in this field has discovered that intensive, repetitive, and task-oriented exercises could help the brain repair itself after damage [4]. However, the patient must be motivated to undergo these exercises, which is a crucial factor to ensure rehabilitation success [5]. According to therapists, the major barrier to conducting rehabilitation programs is encouraging patients to actively participate in the exercises [5], [6].

Another problem is the variety of impairments, which significantly impact the evaluation, development, and planning of rehabilitation programs. That is, an individual could have a specific combination of impairments based on his or her brain injury location, size, and type. A previous work outlined several important factors for ensuring successful rehabilitation therapy [7]. The first factor is that the patients must be challenged when undergoing rehabilitation tasks, but not to the point that they cannot perform the tasks. In this case, the patient's cognitive and 
physical limits must be considered. The second factor is task repetition to ensure the effectiveness of the exercises, in which patient motivation is key. Thirdly, the therapies should be adjusted and defined (on the part of the therapist) according to the patient. In summary, rehabilitation interventions cannot be generalized; they are specific and must be strongly personalized to the individual, which is why they are so expensive.

Considering the discussion above, there is ample room to enhance the quality of life of patients with brain injury [8], [9]. Technological advances and the use of Serious Games for rehabilitation brings about many benefits and fulfills stakeholder needs in various ways [10]. In comparison to traditional rehabilitation exercises, rehabilitation based on games offer numerous advantages such as ensuring the patient stays motivated to play and engage with the exercises via a built-in reward system instead of purely relying on real-world incentives [11]. Additionally, patients often lose interest and give up when it comes to exercises that are very repetitive [12]. This is where gaming offers a considerable advantage, as it can potentially retain patient interest to engage in rehabilitation exercises in a fun, enjoyable way while still stimulating plastic changes in the brain [3]. Besides that, patients can feel safe, immerse themselves in a virtual environment, and pace themselves accordingly through the exercises without exposing themselves to risks [13].

One of the most crucial benefits of this game-based intervention is that even rural patients will get the chance to rehabilitate themselves, as the game systems could be distributed via the Internet [14]. In turn, the time for treatment and cost of human resource for each patient treated could be reduced, besides allowing home-bound patients to easily gain access to the treatments [15]. Several game interventions that have been customized for people with cognitive disabilities have been developed. However, it is challenging to successfully design such games [16], [17]. Previous works in this field lack the understanding of what makes therapeutic games for cognitive rehabilitation effective [13], [18]. Because there is such limited information in this field, game designers and developers are hard pressed to find reliable guidelines for creating successful and innovative Serious Games [19].

One study pointed out that despite the abundance of therapeutic games, only a few have been targeted towards individuals with cognitive disabilities [13]. The most important reasons for this are that cognitive disabilities require an individualized approach, are difficult to categorize, and are heterogeneous. Therefore, it is challenging to design games for cognitive rehabilitation, as the complexity and production cost for these games are usually very high. Besides that, there is not much available knowledge on how to design games that are enjoyable and usable for individuals with cognitive disabilities. To fill this gap, a usable gamebased cognitive rehabilitation method that will also retain patient motivation is proposed via a conceptual framework in this study.

A game prototype was developed in this study to demonstrate the implementation of the proposed framework, called the Rehabilitation Gaming System (RGS). Also, the prototype was evaluated using a questionnaire survey.

\section{MATERIAL AND METHOD}

A design science research method-carried out over two iterations-was used in this research work. A literature review, the survey of the target audience, and collecting of therapeutic game requirements were done in the first iteration. The second iteration uses the findings from the first iteration to construct the main artifact in this study, which is a theoretical framework that will guide developers and practitioners in the design of therapeutic games.

Our earlier work outlines a more detailed description of our design science research methodology [20].

\section{A. Proposed Conceptual Framework}

This study aims to develop a framework that assists rehabilitation practitioners and game developers in designing game-based rehabilitation measures that are usable and enjoyable. Figure 1 illustrates the proposed RGS conceptual framework, which is based on the results of this study and related literature, and targeted towards patients with brain injury [21], [22].

A major aspect of ensuring the effectiveness of the developed therapeutic game is the four components it is based on condition, process, activity, and outcome. These components are further summarized below:

Based on Figure 1:

1) Condition: Condition involves a therapist-conducted patient assessment. This step is crucial to define realistic therapy goals, as the needs, preferences, deficits, and abilities of the patient are identified in this step.

2) Process: Process indicates that the most suitable therapeutic game that will fit the needs of the patients can be created, as this step enables the therapist to pair the predetermined rehabilitation goals with the game characteristics using "tailoring tools."

3) Activity: The patient will finally be able to play the game in "Activity." The effectiveness of the therapists in ensuring that the game activities are tailored to their patients will determine the level of retention of the patients' attention and their engagement with the game. A repeating game cycle will only be established if the therapist has successfully mapped the game's rehabilitation objective to the game's characteristics. This game cycle could lead to continued patient engagement, and in turn result in significant affective and cognitive outcomes.

4) Output: Output represents the specific results of the gameplay activities, which are the patients' achievement throughout playing the game. Therapists can access specific achievement such as a change in the outcome of a patient, which involves assessing-over a period-the patient's improvement. The therapists will also have access to the patient's general achievements such as the total collected assets, time is taken to meet the game objectives and game scores. 


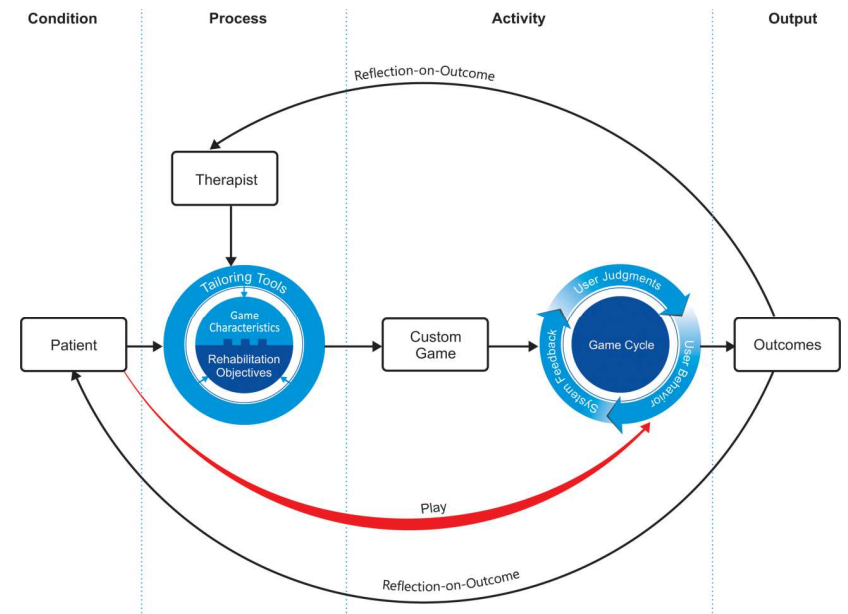

Fig. 1 The main artifact (conceptual RGS framework) of this study

An important thing to note is that patients will only be engaged and motivated to play game-based exercises if they believe they will succeed in the game. The outcomes of their gameplay are a good indicator for this aspect. Besides that, based on the patient outcome, the therapists will be able to assess the affective reactions, task performance level, and changes in skills of the patients. A more detailed description of our proposed framework can be found in an earlier publication [23]. The Rehabilitation Gaming System (RGS) prototype was developed for two main reasons. The first is to demonstrate the implementation of the proposed framework, while the second is as proof of concept for experimental use and evaluation.

\section{B. RGS-Rehabilitation Gaming System}

One foundation for the development of the Rehabilitation Gaming System (RGS) prototype is web-based architecture. To make it easily viewable on the web, the games were created using Adobe Flash. Figure 2 shows the RGS main interface. One requirement for the user to proceed to the next level is that they must first fill the fields that are labeled "password" and "user name". The design environment in the game enables therapists to create and then save the game (Figure 3). In Figure 3, the left-hand side shows the tools for therapists to tailor and build the game, while the right-hand side shows the game design environment.

Therapists will be able to create unlimited numbers of mazes in the game, which are created using the therapist's assessment of their patient's preferences, limitations, and abilities. The design process for the gaming environment in RGS is initiated via tailoring tools. This enables therapists to edit and add questions to the playing field, draw maze pathways, add game objects, and identify opponent behavior such as how they move and react. The game design environment includes a save button and a text box, located at the bottom of the screen. Gameplay instructions and objectives of the game can be entered in the text box. The text that the therapists enter will be launched as part of the game introduction upon patient login to play the assigned game in RGS. The therapists can then save the game after completing the game design via a simple click of the save button.

At the end of this process, the patient will be able to access a set of tasks that are personalized to him or her. To do this, the patient, or for those who have interaction difficulties, the caregivers, must first login to the system. Then, how the game is played and the purpose of the game is given in a short introductory screen. With this, the patients can begin the game (Figure 4). The reader is referred to our earlier work [24] for a more detailed exploration of the design considerations and development of the prototype in this study.

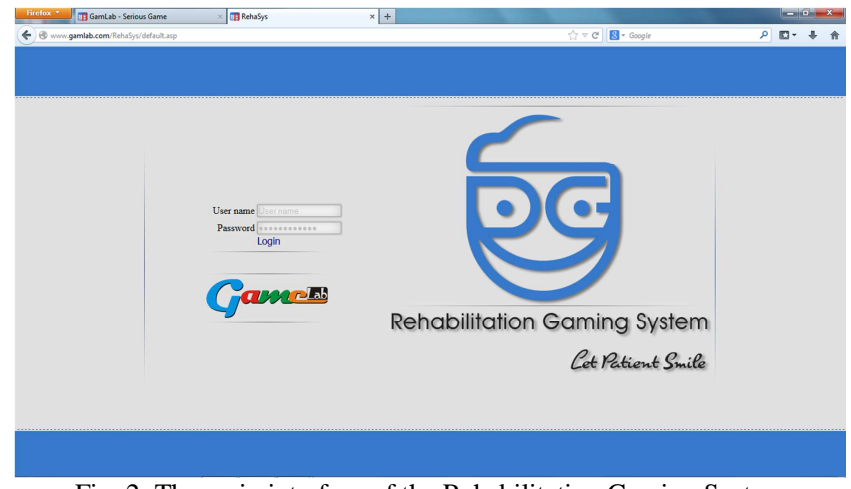

Fig. 2: The main interface of the Rehabilitation Gaming System

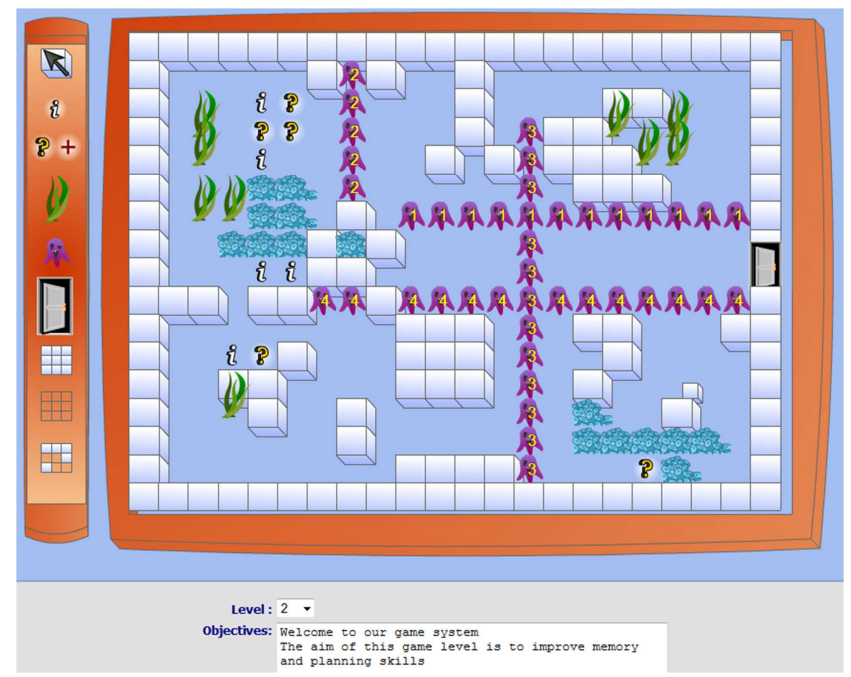

Fig. 3: The design interface that therapists see when creating a game

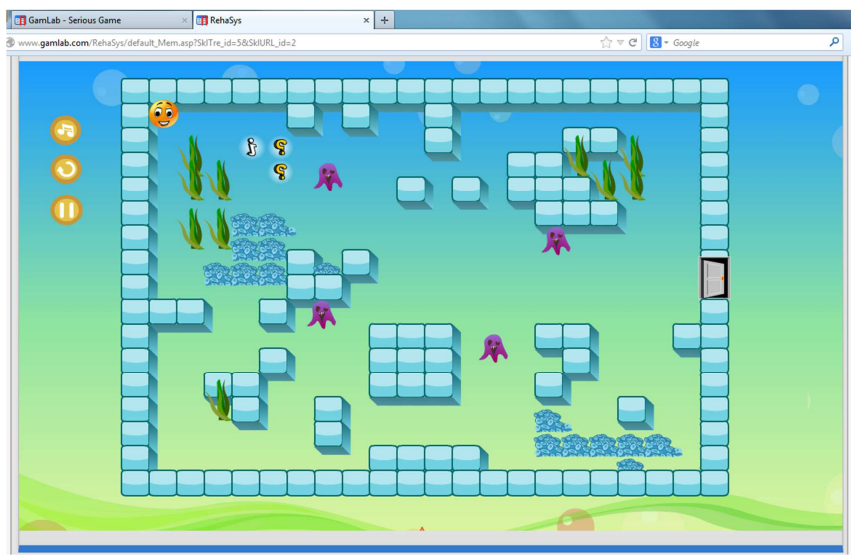

Fig. 4: The gameplay interface that the patient sees when logging in

\section{Evaluation of RGS}

1) Respondents: There are two essential users in this research: the patients and the therapists. The proposed framework is unique in that the therapists are given the important role of tailoring the therapeutic game for their 
patients. From this, we can conclude that therapists are also active users of this game. Therefore, this group was chosen for the prototype usability evaluation in this study.

2) Instrument: Numerous usability questionnaires have been validated and found reliable in this field of study. Some examples are the System Usability Scale (SUS), Usefulness, Satisfaction and Ease of use Questionnaire (USE), Computer System Usability Questionnaire (CSUQ), Questionnaire for User Interface Satisfaction (QUIS), Purdue Usability Testing Questionnaire (PUTQ) and Software Usability Measurement Inventory (SUMI) [25, 26, 27, 28, 29, 30]. Besides focusing on user satisfaction, these questionnaires also focus on the perception of users towards other usability attributes. Available questionnaires were assessed and analyzed to construct a reliable survey instrument for this study. The final questionnaire consists of five constructs: Usefulness, Ease of use, Easy to learn, Satisfaction, and Design/Layout. Previously validated instruments were used to develop the items for measuring the constructs [25], [27], [29], [31]. To ensure these items fit the current research context, they were first modified accordingly.

Three experts carefully reviewed the initial draft with specializations in the fields of statistical analysis, survey development, and research design. These experts also tested the proposed framework for content validity and reliability. Also, a pre-testing stage was also conducted with three Ph.D. candidates from UKM to assess the suitability of the wording, format, and clarity of the questionnaire. Using the results from both tests, the wording in the questionnaire was changed and any confusing items removed.

The respondents were asked to rate the questions using a scale of 1 to 7, indicating, "Strongly disagree" to "Strongly agree," respectively. Participants from Palestine used English to answer the questionnaire. With these results, a higher scale value correlates to higher perceived usability of RGS.

3) Procedure for Data Collection: Due to the therapists' constrained and varying schedules, the participants decided the location and time of the study. It took 30-45 minutes to conduct the study. Since it was the first time that the therapists were using RGS, a brief overview of the system, the role of the study, and purpose of the test were given to them, underlining that the therapists or patients were not being tested for their ability or skill. Then, they were briefed on how to use the system and carry out tasks. To familiarize them with the system, each applicant was briefed about the tasks individually. Subsequently, each was asked to test the various functions of the RGS through performing several tasks in the RGS. First, the therapists must $\log$ in to the system. Then, the therapist must add a new patient. The therapist browsing a patient's profile, after which the therapist will tailor a new game level for the said patient, follows this. Then, the therapist will assign a tailored game to the patient. Lastly, the therapist will log out of the system.

The tasks must be done within a short period. Upon finishing the tasks, the participants were given a questionnaire with responses to be rated from a scale of 1 to 7 .

\section{RESULTS AND DISCUSSION}

Due to difficult-to-work-around schedules and workloads of the therapists, only a $55.55 \%$ response rate (corresponding to 5 of 9 available therapists) was obtained, which is within expectations. The literature shows that $80 \%$ of all usability problems could be determined with only five evaluators. One study argued that any testing conducted after the fifth user would result in the same findings [32]. Also, another study pointed out that potential usability problem could be identified and usability tests conducted with just five participants [33]. Hence, this study is considered to have a sufficient number of participants. Microsoft Excel was used to generate all relevant charts, standard deviations, frequency distribution, and mean for all the ratings. Cronbach's alpha value (Table I) was used to determine the reliability of the constructs in this study, which returned a value above 0.7 ; thus proving the reliability of the questionnaire. After receiving the ratings from each participant, the average was taken and each usability dimension's overall score computed. Subsequently, the results of the questionnaire are discussed in the next section.

\section{A. Layout/Design}

In this phase, the layout suitability of items on the screen displaying the RGS modules is determined. These include the layout of dialog boxes, controls, menus, and information on the screen. The therapists were highly satisfied with the appearance of RGS during running time, portrayed by items 1-10 (Table I). They enjoyed the interface and the theme of the RGS, and found them to be eye-catching and attractive. A previous study emphasized on the importance of aspects such as these and included other criteria to be considered such as the interface colors and icons, interface simplicity, and font size [34]. Another study stressed that the utmost priority for any HCI system is ensuring user interaction with the system is as pleasant as possible [35].

Table II shows that the RGS Design layout dimension obtained an average mean value of 5.94, proving that the therapists trusted the RGS. They also found that the outputs were easy to understand and the system screens were simple.

TABLE I

CONSTRUCT RELIABILITY TEST (CRONBACH'S ALPHA WITH N = 5)

\begin{tabular}{|l|c|c|}
\hline \multicolumn{1}{|c|}{ Construct } & $\begin{array}{c}\text { Number of } \\
\text { Items }\end{array}$ & Cronbach's Alpha \\
\hline Satisfaction & 6 & 0.81 \\
\hline Design/Layout & 10 & 0.81 \\
\hline Usefulness & 10 & 0.93 \\
\hline Easy to Learn & 5 & 0.89 \\
\hline Ease of Use & 6 & 0.93 \\
\hline
\end{tabular}

TABLE II

ITEM MEAN AND STANDARD DEVIATION FOR THE DESIGN/LAYOUT OF RGS

\begin{tabular}{|l|l|c|c|}
\hline No. & \multicolumn{1}{|c|}{ Item } & M & SD \\
\hline 1. & $\begin{array}{l}\text { I would describe the system interface as } \\
\text { uncomplicated and simple }\end{array}$ & 6.0 & 0.70 \\
\hline 2. & $\begin{array}{l}\text { The system presents clear and easy to } \\
\text { understand overall information, e.g., } \\
\text { patient information and game questions }\end{array}$ & 5.6 & 0.89 \\
\hline 3. & On-screen text is easily readable & 5.6 & 0.55 \\
\hline 4. & $\begin{array}{l}\text { The size and quality of the screen } \\
\text { graphics are satisfactory }\end{array}$ & 6.0 & 0.71 \\
\hline
\end{tabular}




\begin{tabular}{|l|l|c|c|}
\hline No. & \multicolumn{1}{|c|}{ Item } & M & SD \\
\hline 5. & $\begin{array}{l}\text { All screens in the system display } \\
\text { consistent graphic elements, e.g., game } \\
\text { characters, icons, labels, and buttons }\end{array}$ & 5.8 & 0.45 \\
\hline 6. & The system makes use of attractive colors & 6.2 & 0.45 \\
\hline 7. & The system uses clear terminology & 5.6 & 0.55 \\
\hline 8. & $\begin{array}{l}\text { The system includes suitably located } \\
\text { buttons }\end{array}$ & 6.2 & 0.84 \\
\hline 9. & $\begin{array}{l}\text { The design of the system is pleasing and } \\
\text { attractive }\end{array}$ & 6.4 & 0.55 \\
\hline 10. & I find the system interface pleasing & 6.0 & 0.71 \\
\hline \multicolumn{2}{|l|}{ Average } & $\mathbf{5 . 9 4}$ & $\mathbf{0 . 6 5}$ \\
\hline
\end{tabular}

In conclusion, the results prove the effective and successful design of the RGS among its target users. In addition, the therapists that tested the RGS also gave a high satisfaction rating.

\section{B. Ease of Use}

The therapists' rating of items 11-16, presented in Table III shows that the RGS was easy to use. RGS has functionalities and services that are clear and an interface that is simple, both of which contributed towards this rating. Besides that, it is easy for the therapists to update and tailor gaming exercises and access required information.

The lowest-rated item-item 15-was related to error handling, with a mean of 5.4. This means that the errors given by the system must be clarified for better guidance of, and understanding for the therapists. Nevertheless, overall, access to information and navigation in RGS were positively rated, as shown in Table III. In sum, the therapists found RGS easy to use.

\section{Easy to Learn}

One study on HCI stated that a key quality attribute to learn a product and its context is learnability [36]. Table IV shows that the dimension "Easy to Learn" for the system obtained a mean value of 5.76. This shows that the users perceived that it was easy to learn to use the system. In other words, they were not faced with a steep learning curve to be able to use RGS efficiently.

\section{Usefulness}

A previous work defines useful technology as up-to-date technology that boosts the job performance of its users [37]. In this study, the usefulness of RGS-as a form of rehabilitation intervention-according to users was tested. The test results in Table $\mathrm{V}$ show that the RGS was a useful tool for the users, represented by the user rating of items 2231.

The lowest mean score-5.4-was observed for item 28, which states, "I will be able to track my patient's progress using the information retrieved from this system". This means that the system has room to improve and provide better suggestions and guidance for therapists to track patient performance. Nevertheless, the "usefulness" of the system was rated a mean of 5.96, indicating that the users perceived the system to be useful in terms of providing adequate functions, meeting rehabilitation requirements, and effectively supporting therapist at work.

\section{E. Satisfaction}

A previous study emphasized the importance of considering the satisfaction factor in any new technology usability evaluation [38]. Hence, in the usability evaluation for this study, the satisfaction factor, indicated by items 3237, was included. The therapists rated these items very highly.

In summary, the therapists found the RGS experience satisfactory and would recommend the system to other professionals, as well as were willing to continue to use the system in the future.

The "Satisfaction" dimension outlined in Table VI shows a mean value of 6.1 , indicating that the respondents were satisfied with the system and intended to use it once it is rolled out.

\section{F. Overall Result}

The system usability was ascertained from the results analysis of the questionnaire survey, where the questions obtained a majority response rating ranging from $5-7$. The scores for the usability measures obtained from the questionnaire survey are visualized using the radar chart presented in Figure 5.

TABLE III

MEAN FOR RGS ITEM "EASE OF USE."

\begin{tabular}{|c|l|c|c|}
\hline No. & \multicolumn{1}{|c|}{ Item } & M & SD \\
\hline 11. & $\begin{array}{l}\text { I find interacting with the system to be } \\
\text { flexible }\end{array}$ & 6.0 & 0.71 \\
\hline 12. & I find that system navigation is easy & 5.8 & 0.45 \\
\hline 13. & $\begin{array}{l}\text { I do not need any technical knowledge } \\
\text { to create a game in the system, which is } \\
\text { easy to do using the tailoring tools }\end{array}$ & 5.6 & 0.55 \\
\hline 14. & $\begin{array}{l}\text { The tailoring tools in the system make it } \\
\text { easy for me to modify existing games }\end{array}$ & 5.8 & 0.45 \\
\hline 15. & $\begin{array}{l}\text { The system allows me to quickly and } \\
\text { easily rectify any mistakes I might have } \\
\text { done }\end{array}$ & 5.4 & 0.55 \\
\hline 16. & $\begin{array}{l}\text { I find that it is easy to use RGS as a } \\
\text { whole }\end{array}$ & 6.2 & 0.84 \\
\hline Average & $\mathbf{5 . 8}$ & $\mathbf{0 . 6 1}$ \\
\hline
\end{tabular}

TABLE IV

MEAN FOR RGS ITEM “EASY TO LEARN"

\begin{tabular}{|l|l|c|c|}
\hline No. & \multicolumn{1}{|c|}{ Item } & M & SD \\
\hline 17. & $\begin{array}{l}\text { I find that learning to operate the system } \\
\text { is easy }\end{array}$ & 5.8 & 0.45 \\
\hline 18. & $\begin{array}{l}\text { Information provided by the system is } \\
\text { easily understandable }\end{array}$ & 5.6 & 0.55 \\
\hline 19. & $\begin{array}{l}\text { I can easily recall where I am in the } \\
\text { system }\end{array}$ & 6.0 & 0.71 \\
\hline 20. & $\begin{array}{l}\text { I can easily recall how to execute tasks } \\
\text { in the system }\end{array}$ & 5.6 & 0.55 \\
\hline 21. & I find that it is easy to learn to use RGS & 5.8 & 0.45 \\
\hline Average & $\mathbf{5 . 7 6}$ & $\mathbf{0 . 5 2}$ \\
\hline
\end{tabular}

TABLE V

MEAN FOR RGS ITEM “USEFULNESS”

\begin{tabular}{|l|l|c|c|}
\hline No. & \multicolumn{1}{|c|}{ Item } & M & SD \\
\hline 22. & $\begin{array}{l}\text { I would save time in cognitively } \\
\text { rehabilitating my patient with this system }\end{array}$ & 5.8 & 0.45 \\
\hline 23. & $\begin{array}{l}\text { I would gain more control over my } \\
\text { patient's rehabilitation activities with this } \\
\text { system }\end{array}$ & 5.6 & 0.55 \\
\hline
\end{tabular}




\begin{tabular}{|c|l|c|c|}
\hline 24. & $\begin{array}{l}\text { I would be able to quickly provide my } \\
\text { patient with rehabilitation training with this } \\
\text { system compared to conventional methods } \\
\text { of rehabilitation }\end{array}$ & 6.0 & 0.71 \\
\hline 25. & $\begin{array}{l}\text { The quality of care that I give would be } \\
\text { improved with this system }\end{array}$ & 6.4 & 0.89 \\
\hline 26. & $\begin{array}{l}\text { I will be able to provide more cognitive } \\
\text { training for my patients with this system }\end{array}$ & 6.0 & 0.71 \\
\hline 27. & $\begin{array}{l}\text { I would increase my work effectiveness } \\
\text { with this system }\end{array}$ & 6.2 & 0.84 \\
\hline 28. & $\begin{array}{l}\text { I will be able to track my patient's progress } \\
\text { using the information retrieved from this } \\
\text { system }\end{array}$ & 5.4 & 0.55 \\
\hline 29. & $\begin{array}{l}\text { I will be able to create games that suit the } \\
\text { needs of my patient's rehabilitation with } \\
\text { this system }\end{array}$ & 6.0 & 0.71 \\
\hline 30. & $\begin{array}{l}\text { I will be able to develop games that are } \\
\text { useful for rehabilitating various patients } \\
\text { with this system }\end{array}$ & 5.8 & 0.45 \\
\hline 31. & $\begin{array}{l}\text { RGS is a tool that is useful for work } \\
\text { purposes }\end{array}$ & 6.4 & 0.89 \\
\hline Average & $\mathbf{5 . 9 6}$ & $\mathbf{0 . 6 9}$ \\
\hline
\end{tabular}

TABLE VI

MEAN FOR RGS ITEM "SATISFACTION"

\begin{tabular}{|l|l|c|c|}
\hline No. & \multicolumn{1}{|c|}{ Items } & M & SD \\
\hline 32. & I feel comfortable using the system & 6 & 0.71 \\
\hline 33. & $\begin{array}{l}\text { This system makes it enjoyable to } \\
\text { construct training games for my patients }\end{array}$ & 6 & 0.71 \\
\hline 34. & $\begin{array}{l}\text { I would be willing to create training } \\
\text { games for my patients using this system }\end{array}$ & 6.2 & 0.45 \\
\hline 35. & $\begin{array}{l}\text { I wish to use this system for my } \\
\text { patients' cognitive rehabilitation } \\
\text { regularly }\end{array}$ & 5.8 & 0.45 \\
\hline 36. & $\begin{array}{l}\text { I will recommend other professionals to } \\
\text { use this system }\end{array}$ & 6.6 & 0.55 \\
\hline 37. & Overall, I am satisfied with the "RGS." & 6 & 0.71 \\
\hline Average & $\mathbf{6 . 1}$ & $\mathbf{0 . 6 1}$ \\
\hline
\end{tabular}

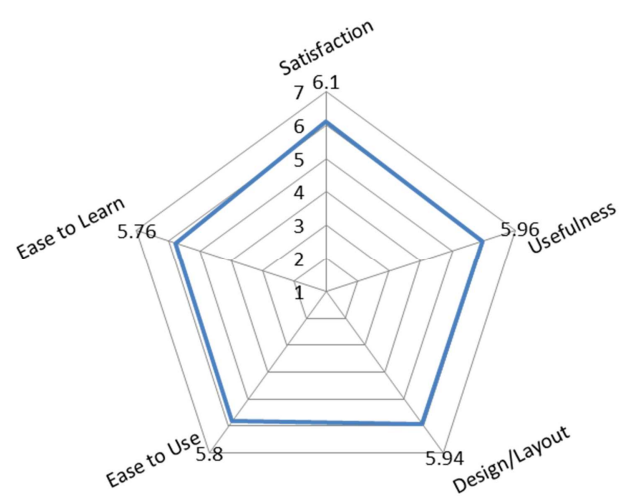

Fig. 5: Radar chart with the metrics Design/Layout, Ease of Use, Satisfaction, Easy to learn, and Usefulness.

From Figure 5, the RGS fulfills all the usability dimensions with mean values for Satisfaction, Ease of Use, Design/Layout, Easy to Learn, and Usefulness of 6.10, 5.80, 5.94, 5.76, and 5.96, respectively.

A mean rating of 5.6 and 4 for a scale of 1-7 and 1-5, respectively, shows that the system has "Good Usability" [39]. In this study, a scale of 1-7 was adopted. Table VII shows that all usability attributes for the RGS prototype achieved a mean of more than 5.6, proving that the system has good usability.

TABLE VII

DIMENSION DESCRIPTION FOR RGS

\begin{tabular}{|l|c|c|}
\hline Construct & M & SD \\
\hline Satisfaction & 6.10 & 0.61 \\
\hline Design/Layout & 5.94 & 0.65 \\
\hline Usefulness & 5.96 & 0.69 \\
\hline Easy to Learn & 5.76 & 0.52 \\
\hline Ease of Use & 5.80 & 0.61 \\
\hline Overall & $\mathbf{5 . 9 1}$ & $\mathbf{0 . 6 2}$ \\
\hline
\end{tabular}

Overall, from the study findings, the proposed framework is proven as both a practical and theoretical contribution to the body of work in this field; especially as a tool to guide game developers and practitioners develop game-based cognitive rehabilitation.

\section{CONCLUSION}

The researcher hopes that practitioners, developers, and game designers would benefit from the framework proposed in this study and find it useful for developing a game-based rehabilitation system, which will in turn significantly impact healthcare systems, patients, and therapists. The RGS (Rehabilitation Gaming System) prototype in this study demonstrated the effectiveness of the proposed framework. The procedures for conventional rehabilitation were simulated in the RGS. Also, the RGS was designed such that therapists will play a necessary role in planning the gamebased rehabilitation intervention. RGS provided tools to help therapists tailor a gaming environment to suit the needs and abilities of their patients, which is crucial in therapeutic game development. The usability of the RGS system was evaluated using a usability questionnaire. The results show that the system has good usability and that the therapists are willing to adopt the system when it is rolled out.

In conclusion, based on the feedback received from the target users, this study was a resounding success. Nevertheless, there is still some room for improvement, especially regarding the usability shortcomings and functionality of the RGS. In particular, RGS should provide a more descriptive error message, clearer instructions, options to avoid errors, as well as suggestions accompanying the errors that therapists encounter when using the system. Another area that can be improved is the tailoring tools given to the therapists, which could include new tools for the tool panel and delivery of more diverse gaming scenarios. One of the respondent feedbacks pointed out the lack of measuring patient progress. Therefore, future work could develop automatic measures to assess improvements in a patient has given a cognitive function as well as measure patient cognitive progress over time. This could prove difficult, however, as there are no automatic measurement systems available yet in the market, which will necessitate scientific validation of any proposed automatic measure via a comprehensive empirical study and a complex debriefing process. In this study, the users came from Gaza, Palestine. Therefore, future work could expand the user base to include other countries, to support the effectiveness of the proposed framework. Additionally, there is potential for the proposed 
framework to be adapted for physical rehabilitation as well. Hence, future work could explore this area further. Although a lot of time and effort would be needed to conduct these future studies, a tremendous outcome would likely result from such an effort.

\section{REFERENCES}

[1] R. De Luca, R. S. Calabrò, and P. Bramanti, "Cognitive rehabilitation after severe acquired brain injury: current evidence and future directions," Neuropsychological Rehabilitation, vol. 28, pp. 879-898, 2018/08/18 2018.

[2] E. Fernandez, J. A. Bergado Rosado, D. Rodriguez Perez, S. Salazar Santana, M. Torres Aguilar, and M. L. Bringas, "Effectiveness of a Computer-Based Training Program of Attention and Memory in Patients with Acquired Brain Damage," Behavioral Sciences, vol. 8, p. 4, 2017.

[3] Y.-X. Hung, P.-C. Huang, K.-T. Chen, and W.-C. Chu, "What do stroke patients look for in game-based rehabilitation: a survey study," Medicine, vol. 95, 2016

[4] J. M. Martínez Moreno, P. Sánchez González, M. Luna Serrano, T. Roig, J. M. Tormos Muñoz, and E. J. Gómez Aguilera, "Modelling ecological cognitive rehabilitation therapies for building virtual environments in brain injury," Methods of information in medicine, vol. 55, pp. 50-59, 2015.

[5] J. Rapolienè, E. Endzelyté, I. Jasevičienè, and R. Savickas, "Stroke Patients Motivation Influence on the Effectiveness of Occupational Therapy," Rehabilitation Research and Practice, vol. 2018, p. 7, 2018.

[6] T. Wolf, S. Kersten, and C. Haas, "Intensive therapeutic treatment in neurorehabilitation - a qualitative analysis from the therapist 's perspective," Journal of Neurology \& Stroke, vol. 8, 2018.

[7] S. Notelaers, T. De Weyer, K. Robert, C. Raymaekers, and K. Coninx, "Design Aspects for Rehabilitation Games for MS Patients," 2010.

[8] R. Sheehan and A. Hassiotis, "Digital mental health and intellectual disabilities: state of the evidence and future directions," Evidencebased mental health, vol. 20, pp. 107-111, 2017.

[9] G.-M. B. Gund, M. P. Jagtap, M. V. Ingale, and R. Patil, "Stroke: A Brain Attack," IOSR Journal Of Pharmacy, vol. 3, pp. 1-23, 2013.

[10] P. Gamito, J. Oliveira, C. Coelho, D. Morais, P. Lopes, J. Pacheco, et al., "Cognitive training on stroke patients via virtual reality-based serious games," Disability and rehabilitation, vol. 39, pp. 385-388, 2017.

[11] A. R. Dores, L. Mendes, I. P. Carvalho, S. Guerreiro, I. Almeida, and F. Barbosa, "Significance of virtual reality-based rehabilitation in acquired brain injury," in Virtual and Augmented Reality: Concepts, Methodologies, Tools, and Applications, ed: IGI Global, 2018, pp. 1586-1601.

[12] R. Friedrich, P. Hiesel, S. Peters, D. P. Siewiorek, A. Smailagic, and B. Brügge, "Serious Games for Home-based Stroke Rehabilitation," in ICIMTH, 2015, pp. 157-160.

[13] J. Torrente, Á. del Blanco, P. Moreno-Ger, and B. Fernández-Manjón, "Designing serious games for adult students with cognitive disabilities," in Neural Information Processing, 2012, pp. 603-610.

[14] D. Bartle, S. Rossoff, D. Whittaker, B. Gooch, K. Kerns, and J. MacSween, "Cognitive games as therapy for children with FAS," presented at the ACM SIGGRAPH 2010 Posters, 2010.

[15] V. T. Cruz, J. Pais, V. Bento, C. Mateus, M. Colunas, I. Alves, et al., "A Rehabilitation Tool Designed for Intensive Web-Based Cognitive Training: Description and Usability Study," JMIR Research Protocols, vol. 2, 2013.

[16] S. Tsikinas and S. Xinogalos, "Designing effective serious games for people with intellectual disabilities," in Global Engineering Education Conference (EDUCON), 2018 IEEE, 2018, pp. 1896-1903.

[17] J. Cheng, "Supporting Therapy-centered Game Design for Brain Injury Rehabilitation,"Ph.D., College Of Computing And Digital Media, Depaul University, 2017.
[18] I. Alaribe, "Design a serious game to teach teenagers with intellectual disabilities how to use public transportation," Procedia-Social and Behavioral Sciences, vol. 176, pp. 840-845, 2015.

[19] Y.-L. Theng, L. Wanzhen, L. Zhiqiang, C. Robert, and R. Pallavi, "Investigation of the antecedents and consequences of gamer satisfaction: An individual perspective," Computers in Entertainment (CIE), vol. 9, p. 15, 2011.

[20] N. A. M. Zin and A. M. Elaklouk, "Design science paradigm in the development of serious game for cognitive rehabilitation," International Journal on Advanced Science, Engineering and Information Technology, vol. 7, pp. 118-124, 2017.

[21] A. M. Elaklouk and N. A. M. Zin, "Requirements for game based cognitive intervention system for acquired brain injury," GSTF Journal on Computing (JoC), vol. 2, 2018.

[22] A. M. Elaklouk, N. A. M. Zin, and A. Shapii, "Investigating therapists' intention to use serious games for acquired brain injury cognitive rehabilitation," Journal of King Saud University-Computer and Information Sciences, vol. 27, pp. 160-169, 2015.

[23] A. Elaklouk, N. Mat Zin, and A. Shapii, "Game Design for Acquired Brain Injury Cognitive Rehabilitation: A Conceptual Framework," in Advances in Visual Informatics. vol. 8237, H. Zaman, P. Robinson, P. Olivier, T. Shih, and S. Velastin, Eds., ed: Springer International Publishing, 2013, pp. 218-230.

[24] A. Shapi'i, N. A. Mat Zin, and A. M. Elaklouk, "A game system for cognitive rehabilitation," BioMed research international, vol. 2015, 2015.

[25] J. P. Chin, V. A. Diehl, and K. L. Norman, "Development of an instrument measuring user satisfaction of the human-computer interface," in Proceedings of the SIGCHI conference on Human factors in computing systems, 1988, pp. 213-218.

[26] A. M. Lund, "Measuring usability with the USE questionnaire," Usability interface, vol. 8, pp. 3-6, 2001.

[27] J. R. Lewis, "IBM computer usability satisfaction questionnaires: psychometric evaluation and instructions for use," International Journal of Human-Computer Interaction, vol. 7, pp. 57-78, 1995.

[28] H. X. Lin, Y.-Y. Choong, and G. Salvendy, "A proposed index of usability: a method for comparing the relative usability of different software systems," Behaviour \& information technology, vol. 16, pp. 267-277, 1997.

[29] J. Kirakowski, "The software usability measurement inventory: background and usage," Usability evaluation in industry, pp. 169-178, 1996.

[30] J. Brooke, "SUS-A quick and dirty usability scale," Usability evaluation in industry, vol. 189, p. 194, 1996.

[31] A. H. Zins, U. Bauernfeind, F. Del Missier, A. Venturini, and H. Rumetshofer, "An experimental usability test for different destination recommender systems," in ENTER 2004 conference. Cairo, Egypt, 2004.

[32] C. W. Turner, J. R. Lewis, and J. Nielsen, "Determining usability test sample size," International encyclopedia of ergonomics and human factors, vol. 3, pp. 3084-3088, 2006

[33] J. Nielsen, Usability engineering: Access Online via Elsevier, 1994.

[34] S. Watzman, "Visual design principles for usable interfaces," The Human-Computer Interaction Handbook: Fundamentals, Evolving Technologies and Emerging Applications, pp. 263-285, 2002.

[35] J. Szalma and P. Hancock, "Task loading and stress in humancomputer interaction: Theoretical frameworks and mitigation strategies," Human-Computer Interaction, p. 91, 2008.

[36] A. Sutdiffe, "Multimedia user interface design," The HumanComputer Interaction Handbook: Fundamentals, Evolving Technologies and Emerging Applications, p. 393, 2007.

[37] F. D. Davis, "Perceived usefulness, perceived ease of use, and user acceptance of information technology," Mis Quarterly, pp. 319-340, 1989 .

[38] A. Sears and J. A. Jacko, The human-computer interaction handbook: fundamentals, evolving technologies and emerging applications: CRC Press, 2007.

[39] J. Sauro and E. Kindlund, "A method to standardize usability metrics into a single score," in Proceedings of the SIGCHI conference on Human factors in computing systems, 2005, pp. 401-409. 